\title{
DONDE EMPIEZA \\ LA SALUD DEL PIE
}

\section{El tratamiento proporcionado por el podólogo en la etapa infantil resulta fundamental para prevenir problemas graves en la edad adulta}

- Alicia de Lara

$\mathbf{E}$ l podólogo se define como el profesional sanitario capacitado para el diagnóstico y tratamiento de las afecciones y deformidades del pie. Una explicación que ofrece una idea algo vaga del papel que desempeñan estos profesionales. Dentro de la podología, existen especialistas en la etapa infantil, pacientes reumáticos, patologías dermatológicas, tratamiento del denominado pie diabético, aplicación de terapias físicas, cirugía, alteraciones biomecánicas, etc. Además, como explica la profesora de Podología de la Universidad Miguel Hernández (UMH) de Elche, Carolina Alonso, es importante tener en cuenta que en muchas patologías sistémicas, los primeros síntomas se producen en el pie, de tal forma que llegan al podólogo como primera vía de entrada y luego los pacientes son derivados a otros profesionales especializados en su patología de base.

La población más asidua al podólogo es la adulta y las personas mayores. Sin embargo, una gran parte de los problemas de los pies se puede y debe detectar y tratar

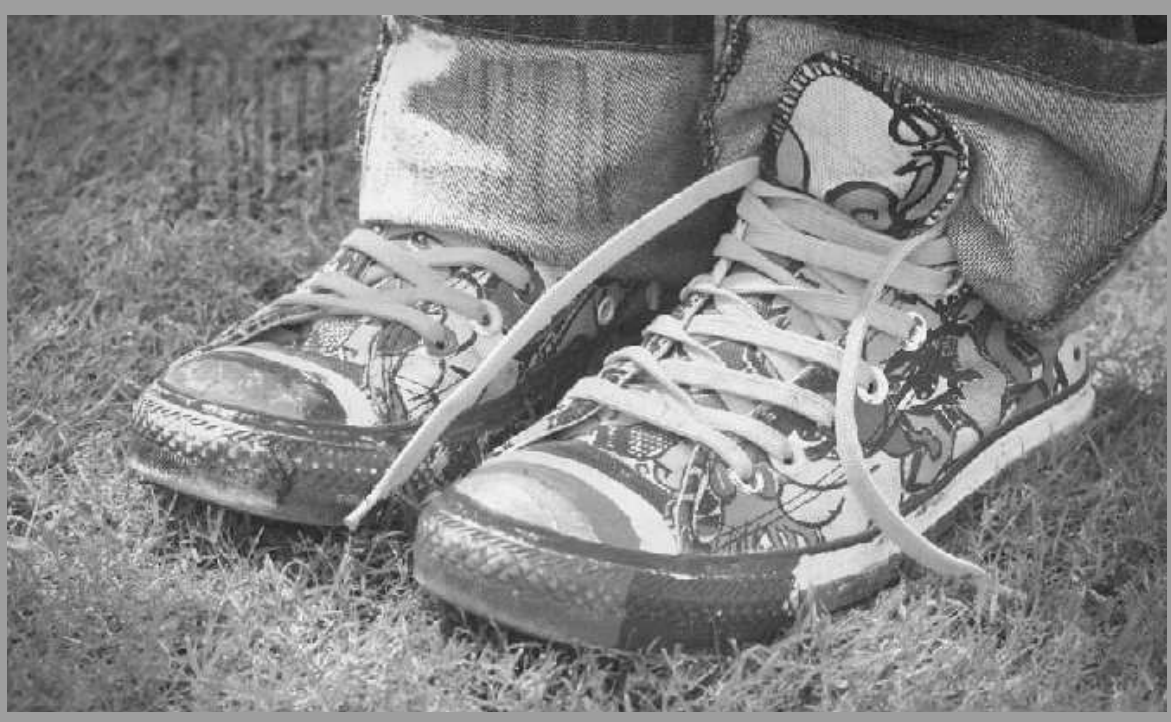

durante los primeros años. Hasta los 14 a 16 años (según el sexo), el pie evoluciona en función de las necesidades del niño. A medida que va creciendo y adquiere la capacidad de bipedestación, se desarrollan todos los huesos y se fortalece la musculatura. "La bibliografía nos dice que puede ser normal que hasta los 6 u 8 años los ni- ños tengan los pies planos", explica el clínico especialista en biomecánica y podología infantil de la UMH Roberto Pascual. Por lo tanto, según el profesor, es importante que antes de esa edad se valore el pie de esos niños para revisar si el grado de pie plano y su flexibilidad están dentro de la normalidad. 


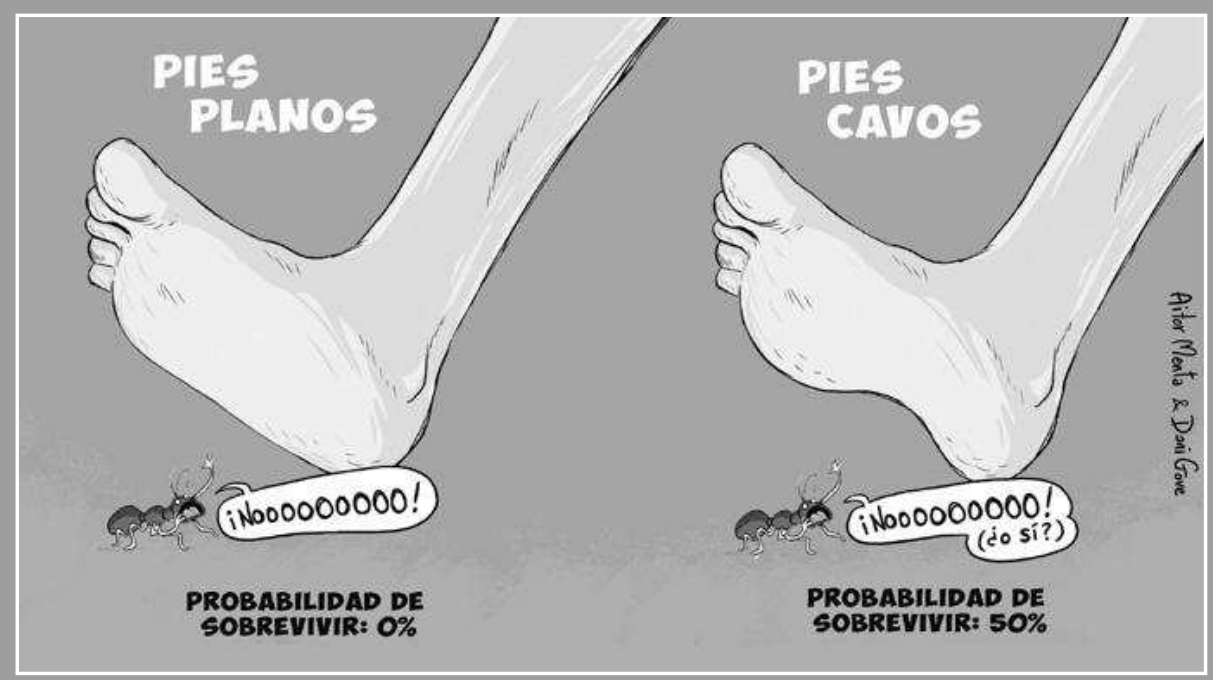

$>$ Desde hace más de una década, la UMH lleva a cabo revisiones de los pies de los menores en colegios alicantinos por medio de un programa de atención primaria de salud podológica escolar. En el último centro donde se hizo la revisión a alrededor de 350 infantes, un porcentaje inferior al $50 \%$ fue informado de que tenían un pie plano no compatible con la normalidad, un dato no muy alto si se tiene en cuenta que la bibliografía señala una prevalencia del pie plano infantil flexible del $44 \%$, según explica Pascual. A estos niños se les aconseja una revisión posterior al podólogo para realizar un seguimiento. "El problema es que los pequeños no se suelen quejar de ningún dolor. Por lo tanto, no hay signo de alerta claro para los padres y puede pasar desapercibido, aunque si ese pie no se trata, lo más seguro es que en edad adulta aparezcan problemas", alerta el profesor.

Existen muchas causas relacionadas con el pie plano infantil. Según Pascual, lo primero que se debe valorar es la flexibilidad. También se tienen en cuenta aspectos como la hiperlaxitud, la obesidad, el genu valgo-también conocido como 'piernas en $x$ '- la diferencia de longitud entre las dos piernas o los acortamientos de la musculatura posterior de las piernas. Todas ellas causas demostradas científicamente que producen que pasados los 8 años ese pie plano no evolucione favorablemente. Pero el profesor también apunta otros factores que deben ser tenidos en cuenta, como es el caso de la genética. "Aunque hay estudios que señalan un aumento de incidencia en casos de historia familiar previa, se desconoce exactamente la causa", matiza el podólogo.

En un pie plano, la parte posterior o retropié se presenta rotada hacia dentro de forma pronunciada y el arco puede llegar a tener contacto con el suelo. Se ha demostrado que los pies planos en edad adulta pueden producir metatarsalgias (dolores en la planta del pie) o talalgias (dolores en la parte del talón). También hay investigaciones que relacionan los pies planos con el hallux abductus valgus, comúnmente conocido como juanete. Los pies planos también están relacionados con dolores a nivel muscular, con lumbalgias y con artrosis de rodilla y de cadera, añade Pascual.

\section{Tratamiento multidisciplinar}

En función de la posible causa de ese pie plano anormal, el tratamiento puede ser una plantilla ortopédica hecha a medida, pero si además el niño presenta problemas musculares, se implicará en el tratamiento a un médico rehabilitador o fisioterapeuta. Incluso si se relaciona con una escoliosis, el tratamiento lo diseñará el trauma con el médico rehabilitador y el ortopeda. De tal manera que tras la revisión de salud podológica en los colegios, se realiza un informe de recomendación al profesional para cada caso no compatible con la normalidad, alrededor de un $30-35 \%$. "Aunque no todos vienen después a realizar la revisión exhaustiva gratuita recomendada. $Y$ esto se debe en parte a la falta de conocimiento general sobre las competencias del podólogo", explica Roberto Pascual.

A pesar de que la figura del podólogo es reciente en España, tanto Pascual como Alonso coinciden en que la podología debería estar incluida en la atención primaria pública porque, a su juicio, es una parte fundamental y porque abarataría determinados tipos de tratamientos que, si no son diagnosticados a tiempo, derivan en procesos más costosos y agresivos para el paciente. A juicio de la profesora, se trata de pensar en soluciones a largo plazo.

De hecho, algunos hospitales privados han empezado a incorporar unidades especializadas en pie diabético o para el tratamiento del pie de deportistas. En estos casos, se incluye al podólogo como parte de los profesionales del equipo formado por diversos perfiles. "Se puede decir que en los últimos años se está abriendo el abanico de salidas laborales", apunta Alonso. Y añade que las posibilidades aumentan gracias a la insistencia de los propios profesionales y al trabajo multidisciplinar, que mejora el conocimiento de lo que puede aportar el podólogo a la calidad de vida del paciente. 


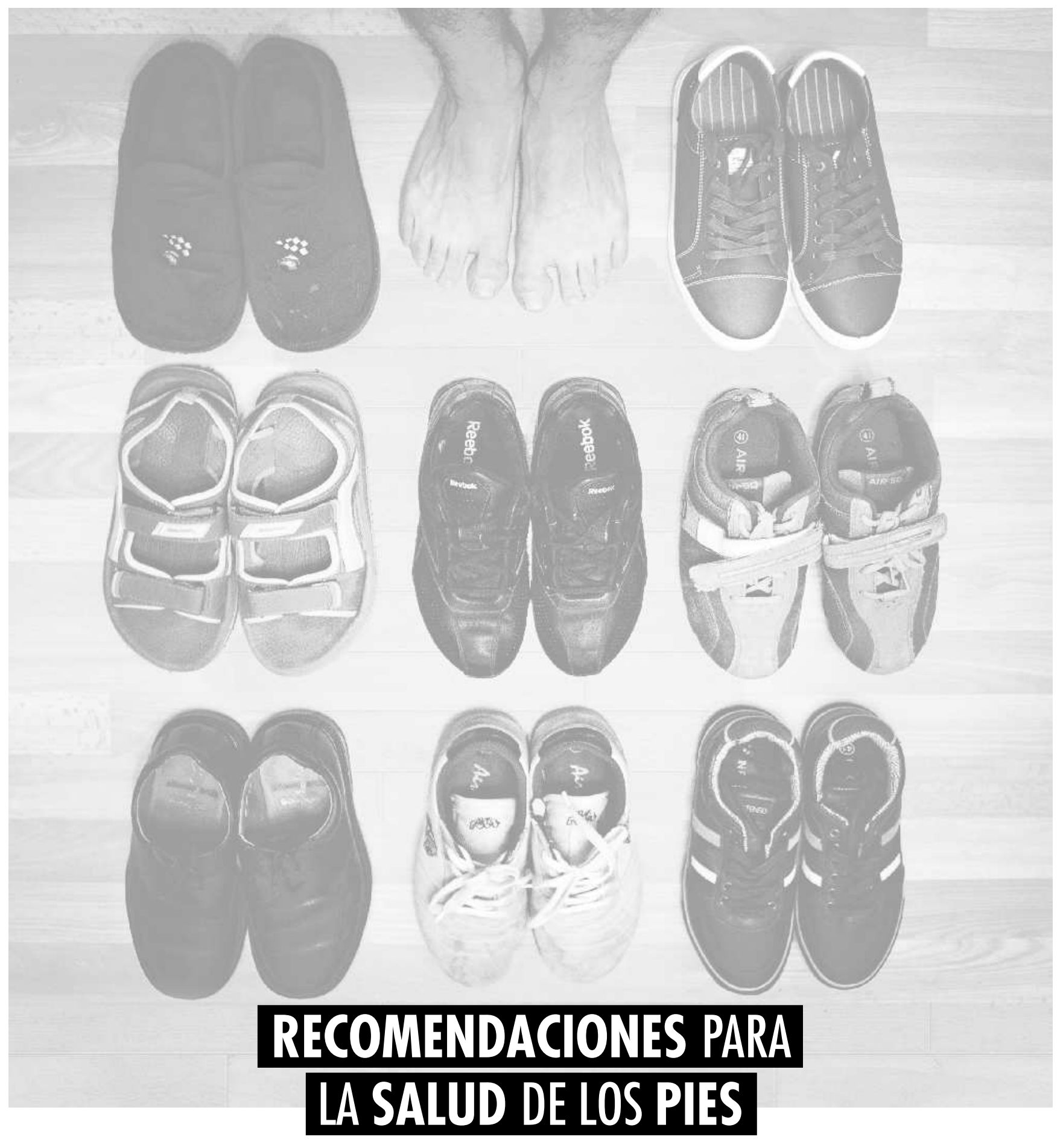

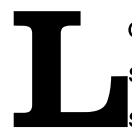

os incómodos callos, provocados por presión concentrada en un punto del pie, ya se trate de una zona concreta -helomas-o cuando el endurecimiento es más extenso -hiperqueratosis- son en realidad mecanismos de defensa ante el roce o el exceso de presión. En esa área, la piel se endurece como medida de protección, pero cuando se engrosa demasiado, llega a comprimir las ramas nerviosas y aparece el dolor.

La profesora del Grado en Podología de la UMH, Carolina Alonso, explica que un tratamiento efectivo para combatir estas moles- tias es una buena hidratación. Aplicar crema en los pies, para tenerlos hidratados $y$, sobre todo, optar por un calzado adecuado, "que es el caballo de batalla y que deriva en importantes problemas", subraya la profesora. Lo recomendable: una suela que no sea excesivamente fina, aunque en el caso de los niños no se recomienda tampoco muy gruesa, y un calzado que vaya sujeto por debajo del tobillo. En el caso de las sandalias y calzado de verano, si llevan contrafuerte en la parte posterior, mucho mejor, porque controlarán la posición del talón. 